\title{
A reforma gerencial do orçamento brasileiro: em busca de múltiplos significados
}

\author{
Carlos Leonardo Klein Barcelos \\ Secretaria de Orçamento Federal \\ Paulo Carlos Du Pin Calmon \\ Universidade de Brasília
}

\begin{abstract}
O objetivo deste trabalho é examinar o processo decisório que culminou na reforma gerencial do orçamento brasileiro (RGO), ocorrida em 2000. Com base na estrutura narrativa - uma técnica desenvolvida por Barzelay e colaboradores (2001) —, são organizados os principais eventos da RGO, a fim de interpretá-los de acordo com o quadro referencial proposto por Allison e Zelikow (1999), que preconizam a existência de três paradigmas, ou "modelos", na análise do processo decisório governamental: o Modelo do Ator Racional (Modelo I), o Modelo do Comportamento Organizacional (Modelo II) e o Modelo da Política Burocrática (Modelo III). Este estudo de caso sugere que o exame do processo decisório do setor público brasileiro, a partir de modelos multiparadigmáticos, fornece uma perspectiva mais rica e mais abrangente dos fatores condicionantes da tomada de decisão e da mudança institucional no governo.
\end{abstract}

Palavras-chave: mudança institucional; modelo decisório; planejamento público; orçamento público.

La reforma de la gestión del presupuesto brasileño: buscando múltiples significados

El objetivo de este trabajo es examinar el proceso decisorio que culminó en la reforma de la gestión del presupuesto brasileño (RGO), ocurrida en 2000. Con base en la estructura narrativa - una técnica desarrollada por Barzelay y colaboradores. (2001) —, son organizados los principales eventos de la RGO, con el fin de interpretarlos según el marco de referencia propuesto por Allison y Zelikow (1999), que preconizan la existencia de tres paradigmas, o "modelos", en el análisis del proceso decisorio gubernamental: el Modelo del Actor Racional (Modelo I), el Modelo del Comportamiento Organizacional (Modelo II) y el Modelo de la Política Burocrática (Modelo III). Este estudio de caso sugiere que el examen del proceso decisorio del sector público brasileño, desde modelos multiparadigmáticos, provee una perspectiva más rica y más abarcadora de los factores condicionantes de la toma de decisiones y del cambio institucional en el gobierno.

Palabras clave: cambio institucional; modelo decisorio; planificación pública; presupuesto público.

Artigo recebido em 24 nov. 2012 e aceito em 17 out. 2013.

Rev. Adm. Pública - Rio de Janeiro 48(1):159-81, jan./fev. 2014 


\section{Managerial reform of the Brazilian budget: in search of multiple meanings}

This paper aims to examine the decision-making process that resulted in the managerial reform of the Brazilian budget (RGO), which took place in 2000. Having the narrative structure as basis - a technique developed by Barzelay and partners (2001) — , we organize the main events of RGO, in order to interpret them according to the reference framework proposed by Allison and Zelikow (1999), who profess the existence of three paradigms, or "models", in the analysis of government decision-making process: the Rational Actor Model (Model I), the Organizational Behavior Model (Model II), and the Bureaucratic Policy Model (Model III). This case study suggests that examining the decision-making process of the Brazilian public sector, by means of multiparadigmatic models, provides a richer and broader panorama of the factors affecting decision-making and government institutional change.

KeYwords: institutional change; decision-making model; public planning; public budget.

\section{Introdução}

Especialmente a partir de meados do século XX, profissionais e pesquisadores do campo da orçamentação pública têm demonstrado grande atração pelo tema da "reforma orçamentária" (Kelly, 2005; Nice, 2002; Jones, 1996; Wildavsky, 1961). Tal fascínio está traduzido tanto nas inúmeras tentativas de reinventar o modo como se processa a orçamentação pública1 quanto na abundante literatura acadêmica que discute o assunto.

Em boa medida, o apetite por remodelar e rotular o orçamento público parece decorrer da necessidade de adaptá-lo às transformações do ambiente em que se insere (Lee, 2008; Rubin, 2006) e da tentativa de reinterpretá-lo em face de mudanças institucionais. Como um sistema aberto, o processo orçamentário reage às metamorfoses políticas, econômicas, sociais e tecnológicas mais intensas, ainda que de forma assimétrica e não sincronizada.

Kelly (2005) esclarece que as reformas orçamentárias possuem natureza cíclica, mas adverte que cada ocorrência deve ser vista como um episódio singular, situado em seu contexto particular. Reformas orçamentárias, de fato, não são geradas espontaneamente nem ocorrem num vácuo social.

A realidade brasileira não parece destoar dessa constatação. Nas últimas cinco décadas o país testemunhou ao menos três importantes episódios de mudança no âmbito da orçamentação pública. O primeiro, que diz respeito à sanção da Lei no 4.320, em 17 de março de 1964, buscou introduzir um modelo de orçamentação voltado basicamente para a padronização e o controle das despesas públicas, dada a balbúrdia que caracterizava as finanças do país no período antecedente (Marques Leite, 1984).

\footnotetext{
${ }^{1}$ Reformas orçamentárias têm ocorrido na maior parte dos países democráticos. Apenas a título de exemplo, ao redor da década de 1990, houve importantes reformas nos Estados Unidos, Reino Unido, França, Nova Zelândia, Austrália e Japão. Mais recentemente, países em desenvolvimento como Chile, Colômbia, Turquia e Brasil também experimentaram uma onda de reformas dessa natureza.
} 
O segundo, que está relacionado com a edição da Portaria Seplan/ $\mathrm{PR}^{2} \mathrm{n}^{\circ}$ 9, de 28 de janeiro de 1974, instituiu para todos os entes da federação a classificação funcional-programática, numa clara tentativa de modernizar e privilegiar a função de planejamento governamental (inclusive através da estruturação do orçamento com base em programas).

Por fim, o terceiro episódio de reforma orçamentária, objeto de análise deste artigo, surgiu no bojo do enxugamento das funções de Estado, iniciado em meados da década de 1990. Conforme registra Core (2007:219), sobretudo a partir do ano 2000, "os processos de planejamento e orçamento assumiram uma feição especial. A experiência acumulada nesta matéria e uma nova concepção de Estado ensejaram a introdução de mudanças estruturais na forma de pensar o planejamento e a orçamentação".

A Reforma Gerencial do Orçamento (RGO), tal como ficou conhecido esse terceiro episódio, abrangeu tanto aspectos relacionados à austeridade fiscal quanto à lógica de planejamento e programação orçamentária. Nesta direção, é possível representar a RGO em função de dois eventos principais: a institucionalização do ajuste fiscal estrutural (substanciada, sobretudo, pela aprovação da Lei Complementar nำ101/2000 — LRF) e a reorientação da lógica de planejamento e de programação orçamentária (operacionalizada por meio da edição de diversos normativos infralegais). ${ }^{3}$

Proposta e aprovada em um ambiente financeiro hostil - o qual impeliu o país a uma forte desvalorização cambial e a um urgente pedido de socorro ao Fundo Monetário Internacional (FMI) - , a LRF propugnava um ajuste fiscal amplo, alinhado às expectativas do mercado financeiro. ${ }^{4}$ Com base em um conjunto de regras presumidamente voltadas à 'gestão fiscal responsável', a LRF tinha a pretensão de "mudar a história da administração pública no Brasil", já que "a partir dela, todos os governantes passariam a obedecer a normas e limites para administrar suas finanças (...)."

Dentre os principais regramentos da LRF se podem citar: a) a limitação dos gastos com pessoal, imposta às três esferas de governo e a cada um de seus Poderes; b) a criação de res-

\footnotetext{
${ }^{2}$ Secretaria de Planejamento da Presidência da República (principal órgão de planejamento e orçamento do governo federal à época).

${ }^{3}$ Refere-se, especialmente, ao Decreto Presidencial no 2.829, de 29 de outubro de 1998, que estabeleceu as novas regras para a elaboração e execução do Plano Plurianual e dos Orçamentos da União; às Portarias Ministeriais no 117, de 12 de novembro de 1998, e no 42, de 14 de abril de 1999, ambas do Ministério do Planejamento, Orçamento e Gestão, que atualizaram a discriminação da despesa por funções (de que tratam o inciso I do $\S 1^{\circ}$ do art. $2^{\circ}$ e o $\S 2^{\circ}$ do art. 8o, ambos da Lei no 4.320, de 17 de março de 1964) e estabeleceram os conceitos de função, subfunção, programa, atividade e operações especiais; à Portaria da Secretaria de Orçamento Federal no 51, de 16 de novembro de 1998, que instituiu o Subsistema de Cadastro de Atividades e Projetos do Sistema Integrado de Dados Orçamentários (Sidor) e estabeleceu o recadastramento das atividades e dos projetos constantes do Projeto de Lei Orçamentária para o exercício financeiro de 1999.

${ }^{4}$ No sentido de oferecer garantias de liquidez e menor risco aos credores da dívida pública.

${ }^{5}$ Cartilha da LRF. Disponível em: <www.portalsof.planejamento.gov.br/bib/legislacao/lei_resp_fiscal/ CARTILHA. pdf. >. Acesso em: 3 abr. 2011.
} 
trições à geração de despesas excedentes no último ano do mandato, sobretudo pela proibição de aumentar despesas com pessoal no segundo semestre, de antecipar receita orçamentária (ARO) e de contrair, nos oito últimos meses, obrigações para as quais não haja recursos em caixa para pagamento futuro, gerados dentro do próprio mandato (dispositivo anticíclico eleitoral); c) o disciplinamento de toda nova despesa corrente de duração superior a dois anos, a qual, para ser efetivada, deverá ter sua fonte de financiamento previamente assegurada; d) a imposição de que os entes governamentais assumam compromissos com metas fiscais e, a cada quatro meses, apresentem ao Poder Legislativo e à sociedade demonstrativos quanto ao cumprimento, ou não, das mesmas; e) a limitação da contratação de dívidas de acordo com determinados limites; f) a proibição de refinanciamentos das dívidas de estados e de municípios; e g) a punição de entes públicos (e, indiretamente, de seus beneficiários) pelo descumprimento dos limites estabelecidos pela lei.

As mudanças na lógica de planejamento e de programação orçamentária, por sua vez, almejavam reorientar o processo alocativo dos recursos públicos para a busca de resultados, avaliados em termos de impactos reais na sociedade (Core, 2007:231), sobretudo, por meio da incorporação de técnicas e ferramentas de gestão típicas do mercado, tais como o desenvolvimento de sistemas de informações gerenciais integradores das diversas bases de dados do governo; a designação de 'gerentes profissionais' para cada 'empreendimento' do plano plurianual; a assunção dos pressupostos metodológicos do 'project management' como 'filosofia de gestão'; os estudos para desenvolvimento regional com base em eixos de integração econômica que indicassem portfólios de investimento ótimos; e a 'atenção estratégica' baseada em controle do fluxo de recursos e gerenciamento de restrições, dedicada a projetos prioritários. Ao relatar a evolução do planejamento no Brasil, o Ministério do Planejamento, Orçamento e Gestão afirma que o objetivo de tais medidas era a busca de maior eficácia, que leva à utilização cada vez maior de mecanismos próximos aos de mercado, à introdução de métodos modernos de gestão e à ênfase em recursos baseados na tecnologia da informação (Brasil, 2002; Barzelay, 2004). Conforme destacou o Manual Técnico de Orçamento para o exercício orçamentário de 2000 (MTO-02/2000), tais iniciativas "representaram um importante passo no sentido da modernização dos processos de planejamento e orçamento (...), tendo como escopo principal a busca para o setor público de uma administração menos burocrática e mais gerencial (...)" (Brasil, 1999:11).

Embora episódios cruciais, como este que envolveu a tentativa de implantar a RGO no Brasil, decorram não apenas de escolhas deliberadas do governo, mas, notadamente, das interações organizacionais e dos desenlaces políticos, a interpretação que tem prevalecido nas análises desse objeto parece restringir-se à perspectiva do governo como um ator plenamente racional e unificado.

Ao interpretar as mudanças da gestão fiscal, do planejamento e da orçamentação pública, assim como as reformas que as conduzem, como meras soluções técnicas e eficientes de 'um governo' bem acoplado, parte importante do significado do episódio fica negli- 
genciada. Por mais rigorosos que pareçam os instrumentos e as ideias indutoras da RGO, os avanços e retrocessos do processo orçamentário não se resumem unicamente à escolha de atores pretensamente racionais. Ainda que esse enquadramento analítico habitual seja útil para alguns propósitos, é evidente que ele deve ser complementado por referenciais baseados em outros fundamentos teóricos, como aqueles cuja atenção está centrada no comportamento das organizações ou, ainda, na conduta dos atores políticos envolvidos com a decisão.

Afinal, além da racionalidade instrumental, os novos moldes da gestão fiscal, do planejamento e da orçamentação refletem também a dinâmica ambiental do poder, as habilidades de liderança, a cultura política, o desenho institucional e a capacidade organizacional das entidades e dos atores envolvidos no processo de reforma (Choudhury, 2007; Green e Thompson, 2001; Wildavsky, 1964, 1992).

De fato, a proposta de analisar reformas orçamentárias a partir de diferentes perspectivas teóricas não é propriamente inovadora. Isso vem ocorrendo porque, ao contrário do que se verifica nos estudos de outros tópicos ligados à economia e finanças, o tema da orçamentação pública carece de teorias e referenciais analíticos desenvolvidos especificamente para o exame de seus objetos.

Enquanto o estudo do comportamento de preços e mercados é orientado pelo paradigma da economia neoclássica, o estudo da política fiscal, como política macroeconômica, sedimenta-se a partir de análises fundadas em modelos neokeynesianos. Analogamente, o estudo das finanças públicas se alicerça em um conjunto de teorias conciliáveis sobre a eficiência do mercado e a composição ótima de portfólios de investimento. Já os estudos do orçamento público e do processo orçamentário, por seu turno, têm sido conduzidos a partir de um mosaico de perspectivas, combinando análises realizadas por economistas, contadores, especialistas em administração pública, sociologia fiscal e direito público. O resultado disso é um conjunto de análises sobre o tema que avança de forma fragmentada, havendo limitada comunicação e competição entre teorias e hipóteses.

Em função disso, a ideia de perceber o processo orçamentário dentro de uma ótica multiparadigmática tem sido exercitada por alguns pesquisadores, conforme se observa, por exemplo, em Bartle (2001) e Kahn e Hildreth (2003).

Somando-se a tal esforço, este artigo se dispõe a abordar a RGO a partir de três diferentes perspectivas: a da escolha racional ou do ator racional (Modelo I); a do comportamento organizacional (Modelo II); e a da política burocrática (Modelo III). ${ }^{6}$

\footnotetext{
${ }^{6}$ Esses três modelos conceituais foram desenvolvidos por Graham Allison em seu mais influente trabalho, o artigo "Conceptual models and the Cuban missils crisis", de 1969. O texto original, que deu origem ao livro The essence of decison, em 1971, foi substancialmente aperfeiçoado na edição que o revisou, em 1999, a qual contou com o importante auxílio do professor Philip Zelikow, que se tornou coautor da obra.
} 
Propostos por Allison, ainda em 1969, e revistos, posteriormente, por Allison e Zelikow (1999), os referidos modelos constituem-se numa das obras mais influentes no âmbito do estudo de processos decisórios e políticas públicas ao longo dos últimos 50 anos. De acordo com Bendor e Hammond (1992:301), antes do trabalho de Allison e Zelikow, os estudos sobre burocracia e política externa, a despeito da riqueza de informação e detalhe, eram "claramente descritivos e sem foco teórico claro". Portanto, uma das virtudes dos modelos de Allison e Zelikow é demonstrar que um trabalho de cunho mais conceitual e abstrato sobre comportamento burocrático no âmbito da política é não apenas viável, mas também desejável (Bendor e Hammond, 1992).

Na medida em que o campo dos estudos orçamentários, em muitos aspectos, se assemelha aos trabalhos sobre burocracia e política externa desenvolvidos na década de 1970, ou seja, marcado por trabalhos tipicamente "descritivos e sem foco teórico", a abordagem multiparadigmática de Allison e Zelikow (1999) demonstra-se promissora.

Assim, a formulação básica de cada modelo será apresentada de acordo com os seguintes aspectos: (a) unidade básica de análise; (b) marco conceitual; (c) padrões dominantes de inferência; e (d) proposições gerais de cada modelo. Por meio de narrativas analíticas históricas são lançadas distintas hipóteses explicativas sobre o episódio. Assim, busca-se oferecer interpretações adicionais a respeito de como o governo decide e atua em face de matérias complexas como esta da RGO.

A fim de dar maior organicidade e consistência ao exercício analítico constante deste texto, aplica-se, de modo simplificado, a estratégia de estudo de caso de mudanças na política de gestão pública desenvolvida por Barzelay e colaboradores (2001).

Além desta introdução, este artigo se divide em mais cinco seções. A próxima seção comenta o desenho da pesquisa e propõe uma guia para seu desenvolvimento. As seções seguintes explicitam os modelos de análise e os articulam no contexto do episódio examinado. Por meio de narrativas, elaboram-se três explicações alternativas e/ou complementares. Por fim, concatenam-se as explicações elaboradas a partir de cada modelo e propõem-se aprofundamentos de pesquisa.

\section{Aspectos metodológicos}

Esta seção apresenta os delineamentos metodológicos que organizam e conduzem a investigação e a análise.

Considerando o duplo objetivo deste texto - qual seja: (a) oferecer interpretações adicionais sobre um mesmo episódio com base em diferentes quadros analíticos; e (b) exercitar a proposta metodológica de estrutura narrativa desenvolvida por Barzelay e colaboradores (2001) —, elabora-se o seguinte diagrama do design da pesquisa. 
Figura 1

\section{Diagrama do design da pesquisa}

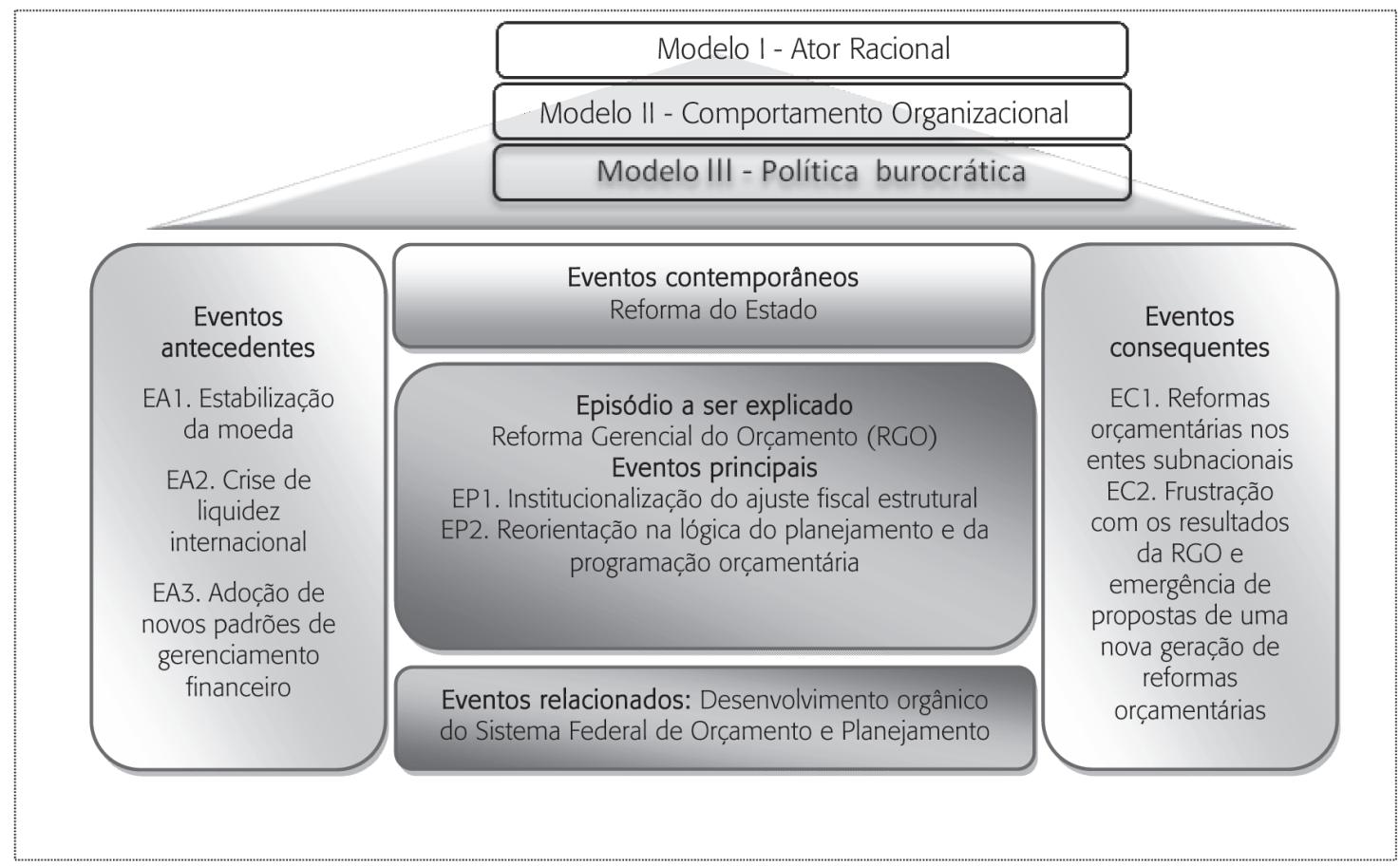

1990.

1996

2000

.2004

2009

Fonte: Elaborado pelos autores.

Os Modelos I, II e III correspondem às três distintas "lentes conceituais" utilizadas para examinar e explicar o episódio da RGO. Os eventos, que se conectam ao episódio, funcionam como estrutura de organização temporal das narrativas.

Conforme esclarecem Barzelay e colaboradores (2001), o episódio representa a ocorrência central e se constitui por eventos principais, elementos diretamente relacionados à experiência a ser relatada.

A estratégia empírica utilizada contempla também a identificação e a análise dos seguintes componentes: (i) eventos antecedentes, que são ocorrências prévias que auxiliam a explicar o episódio; (ii) eventos contemporâneos, que se referem a circunstâncias que ocorreram simultaneamente, contribuindo para a manifestação do episódio; (iii) eventos relacionados, que ocorrem simultaneamente ao episódio e sofrem influência deste; (iv) eventos consequentes, que têm ocorrência posterior ao episódio, claramente conectados a este.

Não obstante a RGO esteja formalmente situada no ano de 2000, parte importante de seu feitio e conteúdo foi esboçada anos antes. Neste sentido, os eventos que a antecederam mereceram especial atenção. 


\section{A perspectiva do modelo do ator racional}

Em grande medida, o Modelo I, ou do Ator Racional, é o paradigma dominante na análise do processo decisório no setor público na América Latina, e se fundamenta no pressuposto de que os atores governamentais possuem preferências completas e transitivas, ou seja, têm preferências racionais e atuam em função dessas. Este pressuposto de racionalidade ampla influencia não apenas as análises sobre o processo decisório no setor público, mas serve também como referência prescritiva e normativa, fundamentando recomendações e avaliações sobre a gestão fiscal, a programação e a execução das políticas públicas no continente.

O Modelo do Ator Racional pode ser descrito, de forma resumida, mediante os seguintes componentes:

a) Unidade básica de análise: políticas públicas são decorrentes de escolhas feitas pelo governo, na busca consciente e deliberada de determinados objetivos. As decisões e ações governamentais dirigem-se ao encontro de objetivos estrategicamente estabelecidos;

b) Marco conceitual: o governo é antropomorfizado e considerado como um ator unitário. Com identidade clara, persegue metas explícitas, que derivam de uma função de utilidade consistente. $\mathrm{O}$ curso de ação tomado é a melhor opção em termos de resposta às oportunidades e ameaças. Há sempre um nexo causal entre a decisão, a ação e a questão que está sendo tratada;

c) Padrões dominantes de inferência: as decisões e escolhas do governo são as que produzem as melhores consequências para o alcance dos objetivos e metas. Desse modo, o padrão de inferência do Modelo I é explicativo, causal e intencional. O desafio é identificar as preferências que orientaram as escolhas;

d) Proposições gerais: a explicitação dos termos de análise (suposições, variáveis e relações internas, por exemplo) que regem a abordagem racional da conduta do governo pode ser sintetizada da seguinte forma - a probabilidade de qualquer ação do governo resulta: (1) da combinação de seus valores e objetivos fundamentais; (2) dos cursos alternativos de ação considerados; (3) das consequências estimadas para cada curso; e (4) do resultado líquido da apreciação de cada alternativa. Diante disso, pode-se deduzir que: (i) a probabilidade de um curso de ação ser escolhido diminui conforme aumentam os custos de sua adoção, isto é, à medida que se reduzem os benefícios ou a certeza de que serão alcançados; e (ii) a probabilidade de um curso de ação ser escolhido aumenta conforme diminuem os custos de sua adoção, ou seja, à medida que se ampliam os benefícios ou a certeza de alcançá-los.

\subsection{Narrativas sobre a reforma gerencial do orçamento na perspectiva do Modelo I}

Dentro desse paradigma, a RGO pode ser entendida como uma atitude deliberada (intencionalidade) do governo (ator monolítico) em resposta às questões (causalidade) que rondavam 
o ambiente doméstico e internacional (cognição perfeita da realidade). Dados três eventos antecedentes (EA1, EA2 e EA3), dois eventos principais sintetizam o episódio da RGO: (EP1) institucionalização do ajuste fiscal estrutural e (EP2) mudanças na lógica do planejamento e da orçamentação.

EA1. Estabilização da moeda: com a conquista da estabilidade monetária, as contas públicas brasileiras evidenciaram rápida deterioração (Giambiagi e Além, 2007). Isso se deve ao fato de que durante o período mais agudo a inflação funcionou como mecanismo de ajuste fiscal. Como as receitas possuíam melhor indexação do que as despesas, o valor real das receitas era recomposto muito mais facilmente, por meio do mecanismo da correção monetária, ao passo que dispendiosas autorizações de gasto, que permaneciam com seus saldos nominais, sofriam a corrosão da inflação. Com a estabilidade, os desequilíbrios estruturais do regime fiscal brasileiro tornaram-se patentes.

EA2. Esgotamento do modelo de financiamento do desenvolvimento: duas condicionantes caracterizam o EA2: (1) a crise de liquidez internacional; e (2) a dificuldade de se ampliar as receitas públicas. A redução dos fluxos financeiros externos ${ }^{7}$ - que tradicionalmente financiavam o desequilíbrio das contas públicas - e a impossibilidade de impor pressão tributária adicional sobre a sociedade serviram de agravante do quadro fiscal, exigindo do Brasil a adoção de ajustes mais enérgicos.

EP1. Institucionalização do ajuste fiscal estrutural: a exata percepção das adversidades do panorama econômico externo e interno motivou o país a agir com firmeza, impedindo que déficits excessivos e reiterados levassem à insolvência financeira do Estado. Em 4 de maio de 2000, o Brasil inaugurou um novo tempo para o controle agregado das contas públicas: "A Lei de Responsabilidade Fiscal [LRF] vai mudar a história da administração pública no Brasil" (Brasil, 2000:2).

Conforme prega a cartilha oficial, a LRF “é importante porque (...) a partir de agora todos os governantes (...) nos três Poderes (...) passarão a obedecer a normas e limites para administrar as finanças, prestando contas sobre quanto e como gastam os recursos da sociedade" (Brasil, 2000:2). Isso melhora a administração das contas públicas no país, pois, "quando o setor público gasta sistematicamente mais do que pode, ou induz a volta da inflação, ou se endivida demasiadamente, criando desequilíbrios macroeconômicos que dificultam o desenvolvimento" (Brasil, 2000:3). De tal perspectiva, a LRF seria o instrumento presumido para reforçar os alicerces do desenvolvimento econômico sustentado, sem inflação para financiar o descontrole de gastos do setor público, sem endividamento excessivo e sem a criação de artifícios para cobrir os buracos de uma má gestão fiscal.

Baseado em tal raciocínio, o redesenho do regime fiscal brasileiro traria como consequência o alcance de três objetivos macroeconômicos relacionados entre si e essenciais à consolidação da estabilidade e à retomada do desenvolvimento: (1) contenção de pressões espe-

\footnotetext{
${ }^{7}$ Explicada em boa medida pelas reiteradas crises econômicas que acometeram muitos dos países emergentes a partir de meados dos anos de 1990.
} 
culativas contra a moeda brasileira; (2) redução da taxa de juros; e (3) aumento da poupança interna, especialmente pelo crescimento substancial da poupança pública (Brasil, 2000).

EA3. Adoção de novos padrões de gerenciamento: com o controle da inflação e as contas ajustadas, o país tratou de desenvolver as condições necessárias para aumentar a capacidade de gestão. Ao perceber a oportunidade favorável durante a elaboração do plano plurianual (PPA) Brasil em Ação, de 1995, o governo brasileiro incorporou técnicas e ferramentas de gestão típicas do mercado corporativo, supostamente capazes de tornar sua atuação mais eficiente, eficaz e efetiva. Dentre elas, merecem destaque o desenvolvimento de sistemas de informações gerenciais, que integram as diversas bases de dados do governo em tempo real; a designação de "gerentes profissionais" para cada "empreendimento" do plano plurianual; a assunção dos pressupostos metodológicos do project management como "filosofia de gestão"; os estudos para desenvolvimento regional com base em eixos de integração econômica; e a "atenção estratégica" baseada em controle do fluxo de recursos e gerenciamento de restrições dedicada a projetos prioritários (Brasil, 2002; Barzelay e Evgeniya, 2004). "A busca de maior eficácia leva à utilização cada vez maior de mecanismos próximos aos de mercado, à introdução de métodos modernos de gestão e à ênfase em recursos baseados na tecnologia da informação" (Brasil, 2002:8).

EP2. Reorientação na lógica do planejamento e da programação orçamentária: contando com a experiência exitosa do Brasil em Ação (Barzelay e Evgeniya, 2004), a reformulação do planejamento e da orçamentação mostrou-se uma alternativa de ação muito oportuna (Brasil, 2000, 2002).

Ao decidir tornar a atuação mais orientada a resultados, o governo estava consciente da necessidade de controlar a gestão "como um todo". Era fundamental assegurar a integração de funções básicas da gestão governamental: planejamento, orçamento, monitoramento, avaliação e controle dos recursos públicos. Nessa direção, elegeu o "problema" — entendido como demandas não satisfeitas, carências e oportunidades identificadas - como a suprema guia da alocação de recursos públicos (Brasil, 2007). Ao "problematizar" a "realidade", o governo atribuiu ao "problema" a centralidade na análise de todas as etapas do ciclo da despesa pública (Core, 2007:249).

À moda da pura lógica das consequências (March, 1994), um "programa orçamentário" nasceria sempre que o governo reconhecesse um problema. Cabe a ele o papel de articular as iniciativas de enfrentamento ao problema, o qual será aferido por indicadores (Grossi et al., 2008:31). Portanto, a "programação" da despesa se traduzirá por alocar recursos públicos em ações (atividades, projetos e operações especiais) capazes de gerar os produtos necessários ao combate das causas do problema. Por meio de metas (volume de produtos) que concorrem para o objetivo do programa (resolver ou aplacar um problema), as ações orçamentárias do governo alinham a despesa pública à obtenção dos resultados pretendidos. ${ }^{8}$ Nesse sentido, programas e ações tornaram-se o fio condutor de cada uma das fases do ciclo da despesa.

\footnotetext{
${ }^{8}$ Neste contexto, o resultado de um programa deve ser entendido como a efetividade no alcance do objetivo proposto, ou seja, a transformação de uma realidade concreta que o programa propôs modificar (Brasil, 2008).
} 
De acordo com o Grupo Técnico Interministerial (apud Garcia, 2000:20):

O processo de planejamento compreenderá a elaboração de diagnóstico da situação existente, identificando e selecionando problemas para o enfrentamento prioritário. Serão formuladas estratégias e diretrizes e definidos objetivos a alcançar para cada um dos problemas selecionados, que serão atacados por conjuntos de ações organizadas em programas. Todos os programas indicarão os resultados pretendidos e as ações que os integram terão metas e custos quantificados. Todos os programas terão sua execução monitorada e com resultados avaliados; a avaliação de desempenho passará a ser critério para a alocação de recursos orçamentários em anos seguintes.

Esse "foi o ponto de partida do processo de transformação da administração burocrática em gestão por resultados" (Brasil, 2002:64). "Essas modificações representam (...) a modernização dos processos de planejamento e orçamento, (...) tendo como escopo principal a busca para o setor público de uma administração menos burocrática e mais gerencial, com efetiva orientação para resultados" (Brasil, 1999:11). Na mesma direção, Garcia (2000) sugere que a intenção das medidas é tornar o planejamento e a orçamentação um processo permanente, obediente a princípios técnicos, tendo em vista o desenvolvimento socioeconômico e a contínua melhoria das condições de vida da população.

\section{A reforma gerencial do orçamento na perspectiva do Modelo de Comportamento Organizacional}

Os fundamentos da perspectiva baseada no Modelo de Comportamento Organizacional, também chamado de Modelo II, são os seguintes:

a) Unidade básica de análise: políticas públicas são geradas a partir da interação de diversas organizações, as quais fazem escolhas específicas. A capacidade organizacional e os produtos gerados por seus programas e repertórios moldam os problemas, determinam o fluxo das informações e criam a aparência que a questão terá ao ser apresentada aos decisores. Nesse paradigma, a categoria fundamental da análise do comportamento governamental centra-se 'nos produtos, nas capacidades e na posição que cada organização desfruta' em face do episódio examinado;

b) Marco conceitual: ao contrário da perspectiva anterior, que preconiza o governo como um ator unitário e antropomorfizado, nesse modelo o governo é descrito como uma constelação de organizações que são acopladas apenas frouxamente, e que obedecem às seguintes características: 1) atividades são programadas e desempenhadas a partir de rotinas preestabelecidas; 2) metas e exigências impostas costumam ser vagas e flexíveis e a organização é julgada principalmente com base na adequação às regras e normas e não em função do seu efetivo desempenho; 3 ) atenção dedicada aos problemas é limitada e seu enfrentamento é 
sequencial; 4) execução confiável das funções críticas depende de processos operacionais padronizados $^{9}$ e de esquemas de redundância; 5) programas e repertórios de solução são desenvolvidos incrementalmente e não podem ser profundamente alterados com frequência; 6) incerteza é mitigada não por meio de estimativas da distribuição de probabilidade das ocorrências futuras, mas sim pela celebração de alianças e elos negociados que assegurem certa estabilidade aos ambientes de atuação; e, por fim, 7) diante de situações que fogem à normalidade, as organizações se engajam na busca de alternativas. Todavia, o estilo de busca e a implementação das soluções sujeitam-se aos valores, à cultura, às rotinas e aos padrões operativos previamente estabelecidos;

c) Padrões dominantes de inferência: as características da ação governamental no período "t" resultam das escolhas que os dirigentes e líderes fizeram em "t-1". Portanto, a capacidade explanatória do modelo de comportamento organizacional reside em analisar a dinâmica de mudanças das rotinas e dos repertórios organizacionais, que tendem a variar de maneira incremental, sujeitando-se a efeitos de dependência da trajetória; ${ }^{10}$

d) Proposições gerais: procedimentos, rotinas, programas e repertórios organizacionais tendem a sofrer mudanças leves ao longo do tempo. Por conseguinte, novas atividades consistem tipicamente de adaptações baseadas em programas e ações que já faziam parte do repertório organizacional. Não obstante, em certas ocasiões específicas, aumenta a propensão de mudanças drásticas: (i) em tempos de grande abundância orçamentária; (ii) quando há prolongados períodos de severa restrição orçamentária; (iii) diante de fracassos desmoralizantes de atuação; e (iv) ante a escândalos dramáticos que comprometam gravemente a imagem da organização.

\subsection{Narrativas sobre a reforma gerencial do orçamento na perspectiva do Modelo II}

Com base nesta lente conceitual, o episódio da reforma orçamentária deve ser visto como produto da atuação e da interação das organizações que o conceberam e implantaram. Note-se,

\footnotetext{
${ }^{9}$ Os procedimentos operacionais padronizados constituem as rotinas que são utilizadas para lidar com situações ordinárias.

${ }^{10}$ Em um processo dependente da trajetória (ou path dependent), as opções pretéritas das organizações seriam condicionantes muito influentes nos momentos de decisão posteriores. Pelo fato de essas escolhas implicarem investimentos iniciais relevantes e difíceis de recuperar, a hipótese de ruptura (ou abandono) da trajetória iniciada no passado representaria não apenas a perda dos recursos já aplicados, mas também a assunção de investimentos adicionais para viabilizar a nova trajetória a ser seguida pela organização. Ademais, em geral, a aprendizagem obtida com o passar do tempo no manejo da estrutura escolhida (seja em termos de regras, sistemas de gestão ou qualquer outro fator institucional) permitiria retornos crescentes de produtividade. Esses mecanismos de 'autorreforço' ou de 'feedback positivo' criariam incentivos em favor de cursos de ação sucessivos que não rompessem com as escolhas passadas, outorgando vantagens à manutenção da trajetória inicialmente escolhida pela organização.
} 
ainda, que processos de alterações drásticas na política de gestão pública são casos específicos de mudança e aprendizagem organizacional. De acordo com o Modelo II, essas mudanças mais drásticas tendem a ocorrer em períodos de profundos cortes orçamentários ou em circunstâncias marcadas por grandes falhas (Allison e Zelikow, 1999).

EA1. Estabilização da moeda: durante o período de alta inflação, o papel das unidades de planejamento e de orçamentação permaneceu atrofiado e obtuso. A expressão "o orçamento era uma mera peça de ficção" resume bem aquela realidade. À medida que as autorizações de despesa eram corroídas pela inflação, os planos (sobretudo) e os orçamentos dissociavamse da realidade, causando certa desmoralização às organizações diretamente responsáveis por suas elaborações (Secretaria de Planejamento e Investimentos Estratégicos, SPI, e Secretaria de Orçamento Federal, SOF, respectivamente). As dotações iniciais, que resultavam do extenuante processo de elaboração orçamentária, eram irrelevantes. “O que valia era a 'luta' por recursos durante a execução" (Grossi et al., 2008:89). Afinal, como destacam Barzelay e Evgeniya (2004:27), "em ambientes de inflação descontrolada ninguém consegue planejar nada a respeito de coisa alguma (...)".

Por conseguinte, as organizações que integravam o sistema orçamentário eram obrigadas a despender, quase que inutilmente, enorme quantidade de recursos apenas para ajustar formalmente o plano e a peça orçamentária aos efeitos da inflação. A concentração de rotinas operativas nesse tipo de esforço suprimia, em grande medida, a oportunidade de se dedicar a assuntos estratégicos.

Com o controle do processo inflacionário, as organizações responsáveis pelas atividades de planejamento e orçamento, bem como rotinas, programas e repertórios, ganharam novos significados. Com essa conquista, as unidades setoriais de despesa passaram a se engajar mais intensamente nas disputas orçamentárias, revalorizando o papel do órgão central e do processo de planejamento e orçamentação em si. "À medida que subitamente a inflação foi controlada, na corrida para a eleição de Cardoso em outubro de 1994, as grandes questões sobre o Estado e o desenvolvimento voltaram à tona" (Barzelay e Evgeniya, 2004:7).

EA2. Reorientação na lógica do planejamento e da programação orçamentária: a crise de liquidez internacional e as dificuldades na obtenção dos recursos fiscais repercutiram negativamente sobre as pretensões de gasto de todos os órgãos da atuação governamental. Contudo, em nenhum deles esse evento fora visto de modo tão ameaçador quanto o fora para a SPI. Afinal, essa restrição representava grave intimidação ao planejamento e real ameaça à grandiosidade do PPA, seu principal produto. Era preciso "encontrar outros mecanismos de financiamento e modelos alternativos de viabilização de investimentos para ampliar a oferta de serviços de interesse público à sociedade", o que certamente não era trivial (Brasil, 2002:62).

Embora não se tratasse de nenhuma circunstância ordinária, cujos repertórios prévios pudessem prontamente lidar, a SPI foi capaz de endereçar algumas soluções satisfatórias ao enfrentamento de seu problema. Adaptando e aprofundando experiências vivenciadas anteriormente, a Secretaria criou um sentido particular à crise, idealizando cenários e formas de investimentos que a auxiliassem a manter a confiança no futuro. Servem de ilustração a isso 
as iniciativas de captação de recursos privados, tais como as privatizações e as tentativas de parcerias público-privadas.

Diante de novas ameaças, as organizações dividem o problema em diferentes componentes e tentam lidar com ele a partir de suas missões, objetivos operacionais, capacidades e culturas organizacionais. Em mensagem presidencial comentando o programa "Gestão empreendedora para o desenvolvimento" do PPA 2000-03, cujo gerente era um reconhecido executivo sênior da SPI, ficou registrado:

A viabilização do projeto de desenvolvimento nacional está apoiada no investimento privado. A participação da iniciativa privada na construção da infraestrutura econômica tem sido crescente nos últimos anos, principalmente nos setores de comunicação e energia. Essa participação, entretanto, precisa ser ampliada para ajudar a suprir as imensas lacunas de infraestrutura necessárias para integrar o País e aumentar a competitividade da economia. A importância que o Governo vem dando a essa questão levou à criação, em novembro de 2000, em parceria com 42 entidades empresariais, da Rede Brasileira de Promoção de Investimentos — Investe Brasil, instituição voltada para a atração de investimentos diretos internacionais e nacionais para o desenvolvimento do País. (Brasil, 2001:2)

Muito se debateu sobre a adequação e o realismo das soluções de financiamento propostas (as parcerias público-privadas até hoje parecem não ter saído do papel ou do imaginário organizacional e as receitas de privatização, em boa medida, foram consumidas pelas taxas de juros extremamente elevadas). Todavia, pouco se tem comentado que o modelo de financiamento proposto refletia apenas parte das rotinas, capacidades, interesses e tradições culturais inerentes às diversas organizações governamentais. As propostas de mudança encabeçadas pela SPI não contavam com o apoio de todos os envolvidos na questão e talvez nem espelhassem, honestamente, as possibilidades do país. Contudo, por um bom tempo, elas asseguraram a atenção e a grandiloquência daquele plano plurianual, cuja construção a SPI liderou.

EP1. Institucionalização do ajuste fiscal estrutural: dentro do Modelo II, a LRF pode ser vista como indiscutivelmente um caso de isomorfismo organizacional. ${ }^{11}$ Trata-se de clara adaptação do Fiscal Responsability Act instituído no âmbito da Nova Zelândia em 1994, especialmente quanto aos estímulos para ampliar a transparência das contas públicas.

Todavia, a estrutura da norma brasileira criou uma combinação única, misturando incentivos de várias naturezas (o que não deixa de ser exemplo de inovação marginal). Resultado de múltiplas interações, a LRF contemplou variadas posições que as organizações

\footnotetext{
${ }^{11}$ Tanto a LRF como a reforma gerencial dos processos de planejamento e de orçamento representam movimentos de mimetismo/isomorfismo organizacional referenciado nas práticas empresariais privadas. Em ambos os casos as mudanças atendem a prescrições de convergência institucional na direção de um capitalismo baseado na economia de livre mercado.
} 
envolvidas na elaboração defendiam (notadamente nas estruturas de fazenda e planejamento federal, no Congresso Nacional, no Tribunal de Contas e também em alguns entes federados de peso). Segundo a classificação proposta por Alesina e Perotti (1995), a LRF é uma instituição fiscal que combina regras numéricas, de procedimento e de transparência.

Apesar do regime federativo, a imposição das regras fiscais no Brasil se deu centralmente e não coordenadamente como ocorreu na União Europeia, por exemplo. Tentando romper com a tradição histórica de frágeis constrangimentos fiscais, o estilo de enforcement preferido pelas organizações "guardiãs" foi o da imposição formal. Ao optar por fixar em lei complementar as regras de procedimento orçamentário, tais como sequestration e pay-asyou-go, as organizações responsáveis pela política macroeconômica assumiram que a rigidez na definição das restrições orçamentárias, ainda que subótima, era preferível em função das idiossincrasias dos entes governamentais. Por outro lado, as organizações contrárias à ideia foram capazes de relaxar as consequências pela desobediência. Houve considerável abrandamento de punições - em comparação às propostas originalmente defendidas pelos órgãos centrais (guardiões).

A presunção era de que a LRF iria "mudar a história da administração pública no Brasil. Através dela, todos os governantes passarão a obedecer a normas e limites para administrar as finanças, prestando contas sobre quanto e como gastam os recursos da sociedade" (Brasil, 2000). Porém, desde que posta em marcha, não são raros os casos em que tem sido flexibilizada e reinterpretada criativamente de acordo com conveniências locais ou momentâneas. De certo modo, isso indica que a "lógica da adequação" (March, 1994) aos costumes e à lógica da política do país também preside a governança fiscal.

EA3. Adoção de novos padrões de gerenciamento: ante o desafio de elaborar um novo PPA para o quadriênio 1996-99, a SPI parecia especialmente preocupada em alcançar melhores resultados no gerenciamento do plano. Muitos dos projetos que passariam a constituí-lo exigiam ações constantes por parte de mais de um ministério (transversalidade setorial), uma ou mais empresas estatais ou, ainda, um ou mais entes federativos (rede interorganizacional). Em termos de fluxos de informação, as organizações setoriais (ministérios e unidades orçamentárias) operavam de maneira compartimentada. O cumprimento de prazos, portanto, era algo que a experiência recente da SPI mostrava improvável. A coordenação era, de fato, tarefa realmente árdua.

Adicionalmente, o quadro fiscal brasileiro continuava a ser fonte importante de embaraços aos interesses da SPI. Por outro lado, a SOF e a Secretaria do Tesouro Nacional (STN), que tradicionalmente executam rotinas voltadas ao controle agregado do teto de gastos, pareciam mais alinhadas e adaptadas às restrições fiscais (há importantes interfaces operacionais e de valores que estas duas organizações conjugam ao cumprir a missão de gestão fiscal da despesa). O cronograma e o volume dos desembolsos para a execução das despesas dependiam da interpretação que ambas as organizações faziam acerca do comportamento de variáveis como receitas correntes, despesas obrigatórias e taxas de juros e câmbio, por exemplo. Essa incerteza quanto aos desembolsos exacerbava os problemas de coordenação e tendia a causar 
atrasos na materialização dos projetos. Isso, sem dúvida, era um grande obstáculo à reputação do plano e à imagem da sua principal protagonista, a SPI.

Em vista disso, a SPI produziu uma série de esforços articulados, os quais podem ser sintetizados como segue:

Para cada empreendimento, foram definidos objetivos e metas a serem atingidas, programação física e financeira, além de controle de custos, prazos e qualidade. Foi designado um gerente, responsável pelo alcance das metas. Ao gerente coube a tarefa de organizar ações em várias áreas, mobilizar recursos, promover parcerias e superar obstáculos para a consecução dos objetivos. Um sistema de informações gerenciais interligava, em tempo real, dirigentes, gerentes e parceiros, permitindo o acesso imediato às informações sobre todos os empreendimentos. $\mathrm{O}$ foco principal do sistema estava no monitoramento físico-financeiro e no compartilhamento de informações sobre restrições e providências, para facilitar o encaminhamento de soluções, sem burocracia. (Brasil, 2000:17)

Kandir, em entrevista concedida a Barzelay e Evgeniya, esclarece: "Desde o início do mandato de Cardoso como presidente, a Secretaria de Planejamento [SPI] estava transbordando de ideias, muitas das quais diziam respeito à elaboração de uma forma adequada de planejamento do desenvolvimento, no âmbito do governo federal" (Barzelay e Evgeniya, 2004:8). "[A SPI] tinha que ser uma secretaria que tomasse posição quanto a questões importantes, propusesse ações e interagisse vigorosamente com os ministérios setoriais", arrematou Marcondes, primeiro secretário da SPI no governo de Cardoso (Barzelay e Evgeniya, 2004:9).

A SOF, por outro lado, fundada em princípios mais conservadores, parecia preferir práticas tradicionais, testadas e seguras, como a divulgação de limites orçamentários por órgão (e não por programa) e as estimativas de tetos orçamentários com base em ajustes incrementais (a partir de alinhamentos da série histórica: $\mathrm{t}=\mathrm{t}-1$, expurgadas as despesas eventuais e adicionadas despesas extraordinárias no presente período, multiplicadas ou divididas por algum fator incremental ou decremental, conforme o caso).

EP2. Reorientação na lógica do planejamento e da programação orçamentária: a concepção de RGO se valeu amplamente de padrões de gerenciamento concebidos ainda no bojo do plano plurianual Brasil em Ação (1995-99). Mas foi a influência da cultura organizacional que permitiu que o episódio irrompesse daquela forma. Os padrões de gerenciamento concebidos não resultaram simplesmente das supostas "adequadas propriedades administrativas" que as ferramentas detinham. Acima de tudo, tais padrões são fruto da identidade que a organização evocava em seu dia a dia e ao olhar para o futuro.

É preciso considerar que até as vésperas da RGO a estrutura da SPI ainda era bastante enxuta, contando com cerca de 40 colaboradores, e até o ano de 1998 não havia na Secretaria nenhum integrante da recém-criada carreira de analista de planejamento e orçamento (APO). 
A fim de moldar e reforçar a identidade e ampliar as condições de sobrevivência organizacional, a SPI defendeu mudanças no sistema de formação de pessoal em Planejamento e Orçamento, as quais foram implantadas entre 1998 e 1999:

Até 1997, o treinamento oferecido aos profissionais aprovados em concurso público tinha um caráter "informativo", com ênfase nas questões relativas ao Orçamento. A partir de março de 1998, a "filosofia" do curso mudou. O treinamento foi ampliado, passando a abranger as áreas de Planejamento, Finanças Públicas e Reforma do Estado. O objetivo foi oferecer aos alunos uma formação mais abrangente, de modo a torná-los agentes de transformação da administração pública. Em 1999, o curso incluiu módulos relacionados com a Economia do Setor Público e a Gestão Empreendedora, para ampliar os horizontes da carreira. (Brasil, 2002:18, grifos dos autores)

Com isso, a SPI passou a contar com um quadro técnico permanente na área, capaz de preservar, aprofundar e difundir o conhecimento gerado ao longo dos últimos anos.

Como se observa, a Secretaria preparava o terreno que julgava propício à consolidação das crenças e valores que buscava reforçar e difundir. "Os esforços dos atores eram influenciados pelas identidades que eles para si evocavam como gestores públicos orientados para resultados, sobre cujos ombros recaíam as responsabilidades de fazer o Brasil em Ação funcionar" (Barzelay e Evgeniya, 2004:26).

As práticas de gerenciamento corporativo, que a SPI defendia com vigor, moldavam um discurso que buscava conciliar a realidade com as possibilidades da organização. Interessada no sucesso das parcerias entre o setor público e os financiadores privados, a SPI dispôs-se a falar uma nova linguagem: "era preciso conquistar a confiança do cliente" e "vestir o traje apropriado". A nova retórica passava longe de tudo que lembrasse as alegorias "políticas", para ficar bem mais próxima do gerenciamento científico de "portfólios" e "empreendimentos", objetos de ação dos novos executivos do planejamento. Assim, o mimetismo organizacional ajudava a galvanizar os signos e símbolos que passariam a estampar os novos produtos que a Secretaria, de fato, lançou.

\section{A reforma gerencial do orçamento na Perspectiva do Modelo da Política Burocrática}

Os elementos fundamentais da Perspectiva do Modelo da Política Burocrática (Modelo III) são:

a) Unidade básica de análise: políticas públicas são geradas a partir de atores influentes, líderes ou dirigentes que ocupam cargos importantes e que estão em posição de decidir. Assim, o comportamento do governo resulta de jogos intrincados, simultâneos e sobrepostos, estruturados por canais reguladores e restritos pela força dos deadlines que se impõem em cada questão. Nesse paradigma, a categoria fundamental da análise dos movimentos da política burocrática "é a capacidade e a reputação que o líder detém" para articular todos os atores necessários ao acontecimento da ação. 
b) Marco conceitual: dirigentes e líderes no governo não formam um grupo monolítico, pois possuem identidade, preferências, objetivos e interpretações heterogêneas, filtrando temas, soluções e oportunidades para decisão de acordo com seus interesses. Outros atores, como grupos de pressão, burocracia, imprensa e público em geral, podem formar círculos concêntricos que se instalam ao redor da arena central, demarcando os limites onde o jogo acontece.

As posições ocupadas delineiam papéis e definem jurisdições, indicando a atuação que os jogadores podem e devem ter. As vantagens e as desvantagens que cada ator usufrui ou enfrenta em cada arena são dadas, em certa medida, pela posição que ocupa. Porém, uma vez que os jogadores são seres humanos, suas habilidades pessoais também interferem no desfecho dos empreendimentos. Logo, a resolução de cada jogo não depende apenas da posição dos jogadores, mas também da personalidade, estilo e carisma que cada jogador é capaz de cultivar.

Jogos de negociação não se dão no vácuo nem de maneira aleatória. Os indivíduos mais importantes são aqueles cujas posições e movimentos os sustentam junto aos canais de ação. Canais de ação representam meios regulares e reconhecidos para atuar sobre questões específicas. Esses canais estruturam os jogos, pré-selecionando os jogadores mais influentes, definindo pontos de entrada e distribuindo as vantagens e desvantagens inerentes a cada jogo. Mais especificamente, definem "quem está com a bola" agora, quem esteve com ela antes e quem estará com ela depois.

As decisões e ações do governo não resultam, portanto, da simples escolha calculada de um agente ou de grupo unificado, tampouco do somatório das preferências dos dirigentes e líderes organizacionais. Com efeito, no contexto de poder compartilhado (em que cada participante tem um juízo próprio e distinto no que tange à importância das questões e à forma adequada de abordá-las), a política torna-se o mecanismo de decisão.

c) Padrões dominantes de inferência: o poder explanatório do Modelo III é obtido pela revelação do jogo - dos canais de ação, dos atores, das posições, das identidades e das preferências dos jogadores que se dividem na atenção do problema central.

d) Proposições gerais: ação não necessariamente pressupõe intenção. Seria algo muito surpreendente a constatação de que a soma das condutas de representantes do governo, em face de determinada questão, fosse exatamente o resultado da ação de um indivíduo ou organização em particular. É mais provável que jogadores isolados, com intenções e culturas diferentes, aportem elementos que se combinarão na configuração de um resultado distinto daquele que cada um havia pretendido singularmente. Portanto, a resultante tende a ser apenas parcialmente consistente com as preferências dos jogadores, sejam eles individuais ou coletivos.

Identidade, preferências, personalidade, estilo, cultura e diversas exigências impostas pela posição política e organizacional de cada jogador moldam o papel, prioridades e questões de interesse. 


\subsection{Narrativas sobre a reforma gerencial dos orçamentos na perspectiva do Modelo III}

Pela lente do Modelo III, a interação política entre os jogadores em posição de decidir determina o desenlace do jogo. A capacidade e a reputação que o líder detém para articular os atores necessários ao acontecimento da ação desempenham um papel fundamental.

EA1. Estabilização da moeda: o controle da inflação no Brasil trouxe impactos eleitorais indiscutíveis. Fernando Henrique Cardoso elegeu-se com apoio suficiente para dar início a diversas pautas da agenda. Todavia, Cardoso sabia o quanto de sua reputação era devido a essa conquista. O medo coletivo da volta das altas taxas inflacionárias e o receio de um consequente desgoverno fizeram da estabilidade um valor coletivo.

EP1. Institucionalização do ajuste fiscal estrutural: nos Modelos I e II, a leitura da vertente fiscal da RGO pressupõe que o desenvolvimento é um problema técnico a ser resolvido por meio de incentivos que corrijam as distorções do mercado político. Todavia, "as instituições e os processos não são neutros ou meramente instrumentais. Eles são o cadinho em que as políticas são forjadas e moldadas, e adquirem a sua verdadeira forma e significado" (BID, 2007:254).

A LRF, como desenlace político protagonizado pelo presidente, é uma resultante intrigante. Cardoso, político-intelectual de esquerda, desde os anos 1960, sempre procurou entender o Brasil e a América Latina a partir de suas especificidades. Num movimento repentino, admitiu trasladar regras fiscais (oriundas de um jogo cuja arena é totalmente diferente) como se fossem meras commodities do tabuleiro.

Mas um ajuste fiscal como esse não se deu apenas pela graça de sua liderança. Uma lei complementar da monta da LRF exigiu apoio qualificado no Congresso e muita simpatia por parte do Supremo (a quem coube julgar as alegações de inconstitucionalidade sobre a matéria). Sabe-se do "jogo pesado que foi jogado" ao redor da arena parlamentar central. O apoio cobrado pelo chamado "baixo-clero" da Casa Parlamentar irradiou diversos escândalos. Representantes localistas se viam ameaçados pela possibilidade de ter suas bases eleitorais atadas pela "camisa de força" da lei fiscal. A totalidade e a natureza dos incentivos que garantiram a sustentação da coalizão vencedora não estão bem claras até hoje, assim como as implicações sociais dessa decisão.

EA3 e EP2. Adoção de novos padrões de gerenciamento e reorientação na lógica do planejamento e da programação orçamentária: o argumento proposto para explicar os eventos EA3 e EP2 é idêntico. Fundam-se na mesma suposição. Evidências sobre o episódio sugerem que a identidade, experiência e reputação do líder-dirigente foram cruciais para que as propostas de mudança na política de gestão do plano plurianual e do orçamento alcançassem o canal que leva ao presidente. O tema ganhou a atenção e o sentido de que precisava.

A assunção dos valores da austeridade, controle e contenção pelo presidente deixava pouco espaço para a discussão de qualquer projeto mais robusto de fortalecimento dos instrumentos de planejamento e orçamento. Todavia, logo após um ano de mandato, Cardoso reconhecera que a agenda de políticas públicas era percebida como "algo pouco além de manter a 
estabilidade macroeconômica" (Barzelay e Evgeniya, 2004). Era preciso mudar isso; e o plano plurianual Brasil em Ação exerceu papel preponderante na realização dessa intenção.

Dentre as lideranças executivas que conduziram tal intento político, José Paulo Silveira foi o mais proeminente, pois fez refletir sua identidade, valores e experiência pessoal por todo o processo de reformulação do planejamento. Antes de assumir a condução da SPI, a convite do então ministro do Planejamento e Orçamento Antônio Kandir, Silveira dirigiu o Programa Brasileiro de Qualidade e Produtividade, o qual envolvia milhares de empresas que estavam tentando se adaptar à rápida liberalização comercial do país. Nessa função, Silveira consolidou sua forte reputação de líder altamente habilitado na condução de empreendimentos em forma de projetos, adquirida originalmente enquanto trabalhara na principal e mais competitiva estatal do país (Barzelay e Evgeniya, 2004).

No decorrer de longa carreira na Petrobras, Silveira havia reestruturado os sistemas de compras da companhia, dirigindo o departamento de pesquisa e desenvolvimento quando a empresa estava estudando como perfurar em alto-mar em profundidades sem precedentes. Ademais, chefiou a unidade de planejamento estratégico quando a estatal se preparava para o fim do monopólio no setor.

Silveira sentia-se atraído pelo "desafio fantástico" de "transformar um estilo burocrático de gestão num estilo de gestão orientado para resultados, isto é, para a introdução de um caráter empreendedor na administração pública". Ele achava que os princípios de gestão de projetos poderiam ser aplicados em todo o governo federal, fazendo do Brasil em Ação uma experiência piloto. (Barzelay e Evgeniya, 2004:2)

Silveira apresentou pessoalmente o projeto de estruturação do plano para o presidente, que, antes mesmo de encerrada a exposição, acenou com a plena concordância. Nas palavras do diretor de Investimentos Estratégicos: "Ele era a representação máxima do que queríamos ver num gerente". Nas palavras do próprio Silveira: “a chave desse processo não é técnica, é uma nova atitude e postura: a do caráter empreendedor. Essa é a essência da mudança gerencial" (Barzelay e Evgeniya, 2004:22).

\section{Conclusões}

O objetivo desse trabalho foi elaborar um estudo de caso sobre o processo decisório que desencadeou a Reforma Gerencial do Orçamento (RGO). Trata-se de uma tentativa de entender a dinâmica orçamentária brasileira a partir de perspectivas não tradicionais. A prática mais comum nas análises sobre o processo orçamentário no Brasil tem sido abordar o orçamento como instrumento de política fiscal ou como elemento de mediação do conflito distributivo entre atores, sejam eles governamentais ou não. Tais análises têm problemas e méritos. No entanto, o objetivo que se estabeleceu aqui é diferente. Com o fito de ampliar o campo de estudos sobre a orçamentação, o foco desse estudo de caso foi considerar o processo orçamen- 
tário como um processo decisório e, para tanto, examiná-lo a partir de uma ótica multiparadigmática.

As opções conceituais e metodológicas inerentes ao estudo ganham relevo ao se constatar que as análises realizadas até o momento tendem a compartilhar um mesmo pressuposto limitante: a predominância da perspectiva da escolha racional ou da "lógica das consequências" nas decisões orçamentárias (March, 1994). Inclusive os estudos que privilegiam a dinâmica das relações intergovernamentais do orçamento, como é o caso dos trabalhos de Figueiredo e Limongi (2002) e Pereira e Mueller (2003), baseiam-se na primeira perspectiva (Modelo I). No entanto, tais análises podem ser aprimoradas se forem complementadas por perspectivas alternativas, centradas na análise do comportamento organizacional e da política burocrática, que privilegiam a chamada "lógica da adequação" (logic of appropriateness; March, 1994).

Com esse intuito, foram adotadas duas estratégias simultâneas. Do ponto de vista conceitual, o estudo de caso fundamentou-se no arcabouço proposto por Allison e Zelikow (1999), sintetizado em três lentes de análise: a do ator racional (Modelo I), a do comportamento organizacional (Modelo II) e a da política burocrática (Modelo III). Do ponto de vista metodológico, o estudo de caso se valeu da estrutura narrativa proposta por Barzelay e colaboradores (2001), o que propiciou que o episódio fosse examinado de maneira temporal, a partir do encadeamento analítico de cinco blocos de eventos: i) principais; ii) antecedentes, iii) contemporâneos, iv) relacionados e i) consequentes.

A estratégia da análise de caso permitiu demonstrar que o quadro conceitual concebido por Allison e Zelikow (1999) favorece o reconhecimento de outros fatores influentes na produção do episódio, tornando mais rica e precisa sua compreensão. Em outras palavras, o quadro conceitual utilizado parece ampliar a "aderência" das explicações à complexidade real do processo decisório governamental, visto que identifica e relaciona outras variáveis importantes, mas pouco evidentes até então.

Por conseguinte, conclui-se que a aplicação comparada dos três modelos amplifica a percepção de analistas e pesquisadores, fornecendo perspectivas úteis ao entendimento das diversas condicionantes que moldam o processo decisório que desencadeia os episódios estudados.

Espera-se que esta primeira abordagem da RGO, como processo decisório que combina distintos paradigmas de análise, estimule a realização de novos trabalhos e que isso se traduza em uma melhor compreensão dos processos decisórios no setor público brasileiro.

Como sugestão de pesquisa futura, propõe-se investigar os motivos pelos quais as mudanças institucionais inerentes à RGO não surtiram os efeitos pretendidos, e como isso afeta as possibilidades de emergência de uma nova geração de reformas orçamentárias.

\section{Referências}

ALESINA, Alberto; PEROTTI, Roberto. The political economy of budget deficits. IMF staff papers, v. 42, n. 1, p. 1-32, mar. 1995. 
ALLISON, Graham T. Conceptual models and the Cuban missile crisis. American Political Science Review, v. 63, n. 3, p. 689-718, set. 1969.

ALLISON, Graham T.; ZELIKOW, Philip. Essence of decision: explaining the Cuban missile crisis. 2. ed. Nova York: Longman, 1999.

BARTLE, John R. Evolving theories of public budgeting. Nova York: Elsevier, 2001.

BARZELAY, Michael et al. Research on public management policy change in the Latin America region: a conceptual framework and methodological guide. International Public Management Review, v. 3, n. 1, p. 20-42, 2001.

BARZELAY, Michael; EVGENIYA, Shvets. Improvising the practices of project-centred strategic planning and delivery: the case of 'Brazil in Action'. In: CONFERENCE ON GENERATION REFORM IN BRAZIL AND OTHER NATIONS, 2004, Rio de Janeiro. p. 1-32.

BENDOR, Jonathan; HAMMOND, Thomas H. Rethinking Allison's models. American Political Science Review, v. 86, n. 2, p. 301-322, jun. 1992.

BID. Banco Interamericano de Desenvolvimento. A política das políticas públicas: relatório de progresso econômico e social na América Latina. Rio de Janeiro: Elsevier, 2007.

BRASIL. Mensagem ao Congresso Nacional. Presidência da República: 2001. Disponível em: <www. planalto.gov.br/publi_04/ colecao/capn01.pdf>. Acesso em: 8 abr. 2009.

BRASIL. Ministério do Planejamento, Orçamento e Gestão. Cartilha de orientação sobre a lei de responsabilidade fiscal. Brasília, 2000.

BRASIL. Ministério do Planejamento, Orçamento e Gestão. Manual Técnico de Orçamento — MTO02. Brasília, 1999.

BRASIL. Ministério do Planejamento, Orçamento e Gestão. Secretaria de Planejamento e Investimentos Estratégicos. O desafio do planejamento governamental. Brasília, 2002.

CHOUDHURY, Enamul. Budgeting as an institutional practice: modeling decision making in the budget process. In: GÖKTUĞ, M. (Org). Handbook of decision making. Nova York: CRC Press, 2007. p. 417-432.

CORE, Fabiano. G. Reforma gerencial dos processos de planejamento e orçamento. In: GIACOMONI. J.; PAGNUSSAT. J. L. (Org.). Planejamento e orçamento governamental. Brasília: Enap, 2007. v. 2, p. 219-261.

FIGUEIREDO, Argelina; LIMONGI, Fernando. Incentivos eleitorais, partidos e política orçamentária. Dados — Revista de Ciências Sociais, v. 45, n. 2, p. 303-344, 2002.

GARCIA, Ronaldo C. A reorganização do processo de planejamento do governo federal: O PPA 2000-2003, IPEA. Texto para discussão no726, Brasília, 2000.

GIAMBIAGI, Fábio; ALÉM, Ana C. Finanças públicas: teoria e prática no Brasil. 3. ed. Rio de Janeiro: Editora Campus, 2007. 
GREEN, Mark T.; THOMPSON, Fred. Organizational process models of budgeting. In: BARLTE, J. (Ed.). Evolving theories of public budgeting. Nova York: JAI Press, 2001.

GROSSI, Bruno C. et. al. Orçamento público: elaboração e execução. Brasília: Enap, 2008.

JONES, L. R. Wildavsky on budget reform. Policy Sciences, v. 29, n. 3, p. 227-234, 1996.

KELLY, Janet M. A century of public budgeting reform: the key question. Administration \& Society, v. 37, n. 1, p. 89-109, 2005.

KHAN, Aman U.; HILDRETH, Bartley. Case studies in public budgeting and financial management. Nova York: Marcel Dekker, 2003.

LEE, Robert. D. Jr. et al. Public budgeting systems. 8. ed. Boston: Jones and Bartlett Publishers, 2008.

MARCH, James G. A primer on decision making: how decisions happen. Nova York: The Free Press, 1994.

MARQUES LEITE, Manoel. 20 anos de padronização de orçamentos e balanços na administração pública brasileira. Análise Econômica, v. 2, n. 3, p. 65-84, 1984. Disponível em: < http://seer.ufrgs. br/index.php/AnaliseEconomica/article/viewFile/10206/ 5946>. Acesso em: 11 jan. 2011.

NICE, David C. Public budgeting. Belmont-CA: Wadsworth Publishing, 2002.

PEREIRA, Carlos; MUELLER, Bernardo. Partidos fracos na arena eleitoral e partidos fortes na arena legislativa: a conexão eleitoral no Brasil. Dados - Revista de Ciências Sociais, v. 46, n. 4, p. 735771, 2003.

RUBIN, Irene S. The politics of public budgeting: getting and spending, borrowing and balancing. 5 . ed. Washington: CQ Press, 2006.

WILDAVSKY, Aaron. Budgeting as cultural phenomenon. In: RABIN, Jack (Ed.). Handbook of public budgeting. Nova York: Marcel Dekker, 1992. p. 51-56.

WILDAVSKY, Aaron. Political implications of budgetary reform. Public Administration Review, v. 21, n. 4, 1961. p. 183-190.

WILDAVSKY, Aaron. The politics of the budgetary process. Boston: Little Brown, 1964.

Carlos Leonardo Klein Barcelos é doutor em administração e analista de planejamento e orçamento da Secretaria de Orçamento Federal. E-Mail: lbarcelos.unb@gmail.com.

Paulo Carlos Du Pin Calmon é PhD em políticas públicas e professor da Universidade de Brasília (UnB). E-mail: calmon@unb.br. 
